\title{
Using Padlet as a pedagogical tool
}

\author{
Ameera Ali \\ York University, Toronto, Canada
}

Keywords: Padlet; student engagement; interactive participation; online learning; Covid19.

\section{The challenge}

The past year has been unprecedented with regard to the swift shift to remote teaching and learning in higher education institutions. As a tutorial instructor of approximately 50 students on a third-year Sociology course, the shift for me involved transitioning my tutorials from a face-to-face environment to a virtual one. The objective of the tutorial space is to further dissect lecture content and course material, draw connections between concepts, and engage in critical and analytical discussions in a highly interactive manner. In my physical tutorial space, student participation often materialised through the use of flow charts, sticky notes and other various tools used to organise and convey information. These tools facilitated student participation by enabling them to learn and create knowledge in a visually engaging and interactive manner. My challenge now was to recreate a remote learning environment which would support and foster similar forms of engagement for students.

\section{The response}

Rather than moving tutorials onto our course Learning Management System (LMS), I strove to provide a platform that mimicked our physical tutorial space in a visually appealing manner; I found this to be achievable through the use of Padlet. Padlet is a tool through which users can create posts that others can engage with, akin to a digital bulletin board. Padlet has been shown to enhance student effort, motivation, participation, learning and cognitive engagement (Gill-Simmen, 2021), all of which are critical to learning 
development in a tutorial environment. Padlet is not a new tool; however, its full efficiency has truly become apparent in the emergency transition to online learning.

Through using Padlet, I also felt that I could effectively implement Young and Wilson's (2000) Ideas, Connections, Extensions (ICE) approach to learning, as students would be able to take ideas from the course, connect them to their socio-cultural contexts, and extend this information to their own lived experiences and the lives of their colleagues in an engaging and digitally interactive manner. Padlet invites students to engage in a fun, meaningful way, which sparks interest and involves both social and academic elements key facets of student engagement (Payne, 2017) which are critical in enhancing learning development. I used Padlet in three different ways.

In the first week of our remote learning dynamic, I created a Padlet using the Wall format, which allows students to create posts in a brick-like layout of different sizes. In this particular activity, I asked my students to create a post connecting a course concept to an element of their individual lives and/or socio-cultural contexts, which is a key objective of sociological learning. Their posts were spread out beautifully over the Padlet for all students to engage with. Padlet was an ideal tool here, as it facilitated learner autonomy, competence and relatedness (Gill-Simmen, 2021).

In our second week, I created a Padlet using the Canvas format, which required students to create a post responding to an initial Sociology-based query that I had posed to them and then engage with one another's posts. The Canvas format was ideal for the activity, as it connected students' responses to one another with arrows whereby they could visually see the comparative elements of their posts. Padlet, here, fostered both independent and collaborative learning engagement (Deni and Zainal, 2018; Gill-Simmen, 2021) and allowed students to make direct connections between their and their colleagues' contributions, through which they drew on critical similarities and distinctions.

Finally, in our third week, I asked students to pose a critical course-focused query as a takeaway from our course to which their classmates were to respond. For this, I created a Padlet using the Shelf format, which allows users to create content in a series of columns; this can be thought of as akin to a forum thread, albeit a more visually appealing one. Queries appeared as separate entries, and each post had several responses from 
students beneath. Through this, students were able to classify and connect content while the visual representation of the information facilitated an engaging way of creating, organising, synthesising and analysing the material (Gill-Simmen, 2021).

Through the alternative means of representation that I was able to facilitate through Padlet, I noticed that student participation increased, as they were able to interact through multiple means of action, engagement and expression, which seemingly improved their interest and engagement (Smith, 2012). I noticed that students who had formerly expressed ambivalence towards participating in our face-to-face tutorials were now actively engaging and were able to directly interact with their peers. I chose to make this a very student-led space; however, I did engage with students' posts occasionally so as to ensure instructor presence in the learning environment (Rapanta et al., 2020). Padlet ensured a highly interactive learning environment, in which students were able to create content, engage with material and participate in critical discussions, both synchronously and asynchronously.

When I spoke informally to students afterwards, they said that they had found Padlet simple and engaging to use. In particular, they mentioned that the Padlets made following conversations and responding to one another easier and more enjoyable than in an LMS, as the content was more visually appealing and easier to access. They appreciated that each 'thread' was visible in one place, and that they were not required to go in and out of forums to engage with other topics. Moreover, students seemed to appreciate the ease with which they were able to embed media into their posts. The 'lifetime' availability of the content created also fostered reiterative learning (Gill-Simmen, 2021) and served as a useful repository for preparing for the course's final exam.

\section{Recommendations}

My experience with using Padlet as a pedagogical tool was certainly a positive one. Padlet is especially useful, as students need not create an account and can participate and ask questions anonymously, which can foster uninhibited critical engagement (Deni and Zainal, 2018). For assessment, Padlet can also be used to assess students' writing skills 
(Jong and Tan, 2021) and allows for students to 'grade' one another's posts with a numeric score, which can foster peer assessment (Adachi et al., 2018),

A caveat that I would like to emphasise is that I had a maximum of 25 students in each of my two tutorials; thus, using Padlet in my experience was very feasible. This may be more challenging in a larger course. Moreover, there are certain accessibility features that are still in the process of being supported by Padlet, which may pose an accessibility limitation for some students. In sum, however, I found this to be a very effective tool to utilise in remote learning contexts.

\section{References}

Adachi, C., Tai, J.H.M. and Dawson, P. (2018) 'Academics' perceptions of the benefits and challenges of self and peer assessment in higher education' Assessment \& Evaluation in Higher Education 43(2), pp.294-306. Available at: https://doi.org/10.1080/02602938.2017.1339775 (Accessed: 13 September 2021).

Deni, A.R.M. and Zainal, Z.I. (2018) 'Padlet as an educational tool: pedagogical considerations and lessons learnt', Proceedings of the 10th International Conference on Education Technology and Computers, pp.156-162. Available at: https://doi.org/10.1145/3290511.3290512 (Accessed: 13 September 2021).

Gill-Simmen, L. (2021) 'Using Padlet in instructional design to promote cognitive engagement: a case study of undergraduate marketing student', Journal of Learning Development in Higher Education, (20). Available at: https://doi.org/10.47408/jldhe.vi20.575 (Accessed: 13 September 2021).

Jong, B. and Tan, K.H. (2021) 'Using Padlet as a technological tool for assessment of students' writing skills in online classroom settings', International Journal of Education and Practice, 9(2), pp.411-423. Available at: https://doi.org/10.18488/JOURNAL.61.2021.92.411.423 (Accessed: 13 September 2021). 
Payne, L. (2017) 'Student engagement: three models for its investigation', Journal of Further and Higher Education, 43(5), pp.641-657. Available at: https://doi.org/10.1080/0309877X.2017.1391186 (Accessed: 13 September 2021).

Rapanta, C., Botturi, L., Goodyear, P., Guàrdia, L. and Koole, M. (2020) 'Online university teaching during and after the Covid-19 crisis: refocusing teacher presence and learning activity', Postdigital Science and Education, 2(3), pp.923-945. Available at: https://doi.org/10.1007/s42438-020-00155-y (Accessed: 13 September 2021).

Smith, F.G. (2012) 'Analyzing a college course that adheres to the Universal Design for Learning (UDL) framework', Journal of the Scholarship of Teaching and Learning, 12(3), pp.31-61. Available at:

https://scholarworks.iu.edu/journals/index.php/josotl/article/view/2151 (Accessed: 13 September 2021).

Young, S.F. and Wilson, R.J. (2000) Assessment and learning: the ICE approach. Winnipeg: Portage \& Main Press.

\section{Author details}

Ameera Ali is currently a Post-Doctoral Researcher in York University's teaching and learning centre, the Teaching Commons. Her current research is informed by principles of accessibility, equity, diversity and inclusion, and investigates university students' experiences of teaching and learning. 